\title{
Formação de educadores com foco na reflexão do cotidiano escolar
}

\section{Teacher training focusing on discussions of the school routine}

Maria Emiliana Lima Penteado é doutoranda do Programa de Educação: Psicologia da Educação da Pontifícia Universidade Católica de São Paulo. Mestrado concluído em 2013, no mesmo programa, com a dissertação "Formação em serviço: análise de uma proposta de formação construída por e para educadores", origem do presente estudo. Participante do grupo de pesquisa: Atividade Docente e Subjetividade (CAPES/CNPQ). Tutora do Programa Educação: Formação de Formadores (PUCSP). Pedagoga e Psicopedagoga com 20 anos de experiência na Educação Pública da cidade de São Paulo.

Contato: emipenteado@gmail.com

\section{Resumo}

0 cotidiano escolar é ideologicamente constituído e reproduz comportamentos e discursos culpabilizantes do fracasso escolar. 0 objetivo deste estudo é apresentar o processo de constituição de uma proposta específica de formação em serviço com ênfase na reflexão do cotidiano escolar a partir de práticas pedagógicas. A base teórico-metodológica é a Psicologia Sócio-Histórica. Utilizaram-se documentos e entrevistas reflexivas (SZYMANSKI, 2011) para produção dos dados e, na análise, os "núcleos de significação" (AGUIAR \& OZELLA, 2006, 2013). Os resultados revelaram que dar visibilidade a trabalhos bem sucedidos e criar espaço para discutir a realidade escolar possibilitaram valorizar os educadores, pensar coletivamente nos impedimentos de outros seguirem em direção parecida e, ainda, implicaram na tentativa de superar a dicotomia entre teoria e prática, a fim de se alcançar a práxis.

Palavras-chave: Formação em serviço. Cotidiano escolar. Práxis. 


\begin{abstract}
The school routine is ideologically established and reproduces behaviors and guilt-inducing speeches of academic failure. The purpose of this study is to present the process of constitution of a specific proposal of inservice training with an emphasis on the reflection of school routine from pedagogical practices. The theoretical and methodological basis is the Socio-Historical Psychology. We used documents and reflective interviews (SZYMANSKI, 2011) for data production and in the analysis, the "núcleos de significação" (AGUIAR \& OZELLA, 2006, 2013). The results showed that giving visibility to successful work and creating space to discuss the school reality enabled the enhancement of educators, the collective thinking of the impediments that others followed in a similar direction, and also tried to overcome the dichotomy between theory and practice in order to achieve praxis.

Keywords: In-formation training. School routine. Praxis.
\end{abstract}

\title{
Introdução
}

Os professores do ensino público brasileiro são, na maioria das vezes, culpabilizados pelo fracasso da educação. Em especial, a influência da mídia reforça essa culpa com discursos ideológicos que apresentam meias verdades em relação à responsabilidade do professor sobre o ensino e a aprendizagem dos alunos. Os discursos muitas vezes escamoteiam problemas e responsabilidades do poder público, que deveria oferecer condições salariais e de trabalho dignas para o professor se desenvolver e se realizar profissionalmente. Nóvoa (1998) ressalta que os professores encontram-se perante vários paradoxos que incluem a desconfiança profissional, acusados de formação deficiente, e cobrança da sociedade, por serem considerados elementos essenciais para o progresso social e cultural.

Por outro lado, no meio docente, há um discurso recorrente para eximir ou diminuir a responsabilidade do professor em relação às mazelas da educação, em especial a não aprendizagem dos alunos. Muitos professores atribuem as causas do fracasso escolar a fatores "externos" à escola e às práticas de sala de aula, esquecendo-se muitas vezes de se incluírem na complexa arena do momento histórico e político educacional em que estão 
inseridos. Dessa maneira, eles tendem a assumir discursos e comportamentos paralisantes, insistindo em acomodar-se, colocando a escola como uma instância isolada do seu tempo histórico, social e político. Porém, no cotidiano, a realidade "extraescolar" bate à porta da escola e exige dela movimento, posicionamento e mudança.

0 cotidiano escolar é multifacetado e constituído por fatores ideológicos. Encontramos frequentemente nesse cotidiano escolar comportamentos e discursos reproduzidos e, muitas vezes, cristalizados nas falas de professores, pais e alunos sobre a culpa em relação ao fracasso escolar.

No que diz respeito à influência ideológica no processo educacional, Severino (2002) traz uma rica reflexão. Ele afirma que a educação pode servir como instrumento para reforçar a ideologia dominante por meio da reprodução, mas também aponta caminhos de transformação e superação. 0 autor afirma que "o processo educacional reforça a dominação na sociedade cujos mecanismos reproduzem, sem reelaboração, as referências ideológicas e as relações sociais" (p. 75). Mas, em seguida, contrapõe tal afirmação ao dizer que a educação pode assumir, contraditoriamente, uma posição de resistência a conteúdos ideológicos, criticando-os e superando-os. Nesse sentido, a educação pode vir a ser uma prática transformadora.

Neste estudo, que tem como objetivo apresentar o processo de constituição de uma proposta específica de formação em serviço, o pensamento de Severino sobre o poder da educação em manter a opressão ou assumir uma postura contrária, alinha-se com o propósito dos educadores que a idealizaram. Assim como o autor, os educadores acreditaram que a escola pode vir a ser um lócus de resistência e possibilitar mudanças, favorecendo assim a transformação social.

Os idealizadores dessa proposta formativa assumiram uma posição crítica diante das políticas públicas implantadas pelos governos. E, assumindo essa posição, em sua luta diária, tentaram criar situações de resistência às imposições verticalizadas. Para isso, em vez de sucumbirem, resolveram olhar para o que é posto e confrontar com a realidade vivenciada. Assumiram o compromisso de ir além das queixas sobre a profissão, como também das formações que não atendem às expectativas da escola real.

E assim, usando as lentes de uma perspectiva crítico-reflexiva, educadores criaram uma proposta de formação em serviço 
preocupada com uma educação que atenda a formação humana. Para isso, apostaram em olhar para a realidade da escola e nas potencialidades do coletivo. Acreditaram que a escola é o lócus de possibilidades, pois nela, encontram-se as grandes contradições da sociedade. Sabemos que a escola não nasceu para todos. A estrutura social a obrigou a incorporar todos na escola. Portanto, a escola ainda conserva a matriz excludente.

Aqueles que optaram por construir uma proposta de formação que atendesse suas expectativas entenderam que a escola, mais especificamente o grupo de professores, precisava urgentemente apropriar-se dos seus problemas para encontrar soluções adequadas. Como fazer isso? Para eles, o ponto-chave era olhar com clareza a realidade de cada escola, reconhecendo limitações, construindo possibilidades e assumindo o compromisso de ser professor no momento histórico em que se encontravam. Tudo isso sem inviabilizar a luta por melhores condições de trabalho. Aliás, o comprometimento com a realidade traz mais clareza para lutar a favor da profissão docente.

Sendo assim, os pressupostos adotados por esta proposta de formação de educadores foram pautados na formação e autoformação do educador, entendendo-se que no ato de formar, o educador também se forma, conforme argumentava Paulo Freire. Trata-se de uma proposta de formação pensada e organizada coletivamente; preocupada em valorizar o profissional da educação; voltada para a autoria do pensar docente, reconhecendo-o como intelectual da sua área de atuação; gestada a partir do cotidiano escolar e da prática do professor; disposta a atender às necessidades reais da escola; em dar visibilidade às boas práticas pedagógicas, que, de algum modo, conseguiram atender às expectativas da realidade local; intencionalmente pensada para refletir a prática educativa, o fazer diário, enfim, o cotidiano escolar em busca de melhorar as condições de ensinoaprendizagem.

Cabe ressaltar que este artigo apresenta parte da análise do processo de constituição de uma proposta específica de formação em serviço, objeto de estudo da dissertação de mestrado da autora, intitulada Formação em serviço: análise de uma proposta de formação construída por e para educadores. Portanto, apresentam-se a seguir os pressupostos teórico-metodológicos nos quais a pesquisa, base deste artigo, foi fundamentada. 


\section{Pressupostos teóricos-metodológicos: a Psicologia Sócio-Histórica}

Sob a perspectiva da Psicologia Sócio-Histórica, o homem é um ser social e histórico; um sujeito que atua no mundo, tranformando-o e transformando-se mutuamente. 0 homem é historicamente constituído e, desse modo, tem condições de interferir na história, transformar a natureza e criar suas próprias necessidades. Necessidades que irão gerar outras e, assim, estabelecer um movimento complexo de busca constante de transformação no e do mundo para atender as necessidades humanas.

Fundamentada no marxismo, a Psicologia Sócio-Histórica assume o método e os princípios teóricos do materialismo histórico e dialético, formulados por Karl Marx (1818-1883) e Friederich Engels (1820-1895), principalmente no que diz respeito ao entendimento do sujeito a partir das relações sociais e a origem social da consciência humana. Vigotski, fundador da Psicologia Sócio-histórica, procura não dicotomizar nem o real, nem o humano. Bock (1999) esclarece que as diversas abordagens que analisam o indivíduo como um ser isolado, abstrato, estático, independente de um contexto relacional e social merecem críticas. O homem precisa ser compreendido como um sujeito histórico, crítico e transformador da realidade.

Esta pesquisa, pautada nessa perspectiva de homem, adotou uma visão não linear, ou seja, uma visão dialética da realidade. A dialética aqui é entendida no sentido marxista, como ideia de oposição, de movimento contraditório e transformador. 0 pesquisador, ao adotar o pensamento dialético, próprio da visão sócio-histórica, depara-se com um grande desafio. Este desafio é a exigência de um trabalho minucioso, cuidadoso e intenso, pois se trata de pensar a realidade como um todo; é preciso estudar seus processos constitutivos bem como a forma como eles se articulam entre si. Para conhecer a totalidade, não basta apenas obter informações e refletir: é necessário conhecer a estrutura dialética do todo, seu processo e suas determinações, sua história.

Vigotski (2007) defende o estudo do fenômeno na sua historicidade. Segundo o autor, estudar algo historicamente significa analisá-lo em seu processo de mudança, considerando todas as fases do desenvolvimento, pois "[...] é somente em movimento que um corpo mostra o que é" (p. 68). 0 movimento de apropriação da realidade ocorre numa relação dialética. Portanto, a partir da análise do processo e da gênese desse movimento é que 
poderemos descrever, explicitar e explicar a essência do fenômeno na sua totalidade. É claro que o todo é criteriosamente analisado em suas partes para, a partir daí, se entender melhor as conexões existentes em todo o processo analisado.

Para isso, tomam-se como sustentação metodológica os três princípios apontados por Vigotski (1984, 2007), a saber: 1) Análise de processos e não de objetos: significa apontar para a importância do movimento, identificado nos processos e não nos objetos; 2 ) Explicação versus descrição: significa que apenas a descrição do fenômeno não pode revelar seu processo de determinação; 3) 0 problema do "comportamento fossilizado": significa compreender o processo de desenvolvimento de determinado fenômeno, contemplando todas as suas dimensões, indo além da aparência, tendo em vista que esta já não revela sua essência por ter perdido sua aparência original. Esse princípio se torna uma síntese dos anteriores. Para o autor, "o método é, ao mesmo tempo, prérequisito e produto, o instrumento e o resultado do estudo" (Vigotski, 2007, p. 69).

0 referencial teórico-metodológico da perspectiva da Psicologia Sócio-Histórica serviu como aporte para compreender, analisar e explicar o processo de constituição da proposta específica de formação em serviço estudada e apresentada neste artigo, considerando as múltiplas determinações históricas, sociais e culturais, bem como os fatores ideológicos nelas impressas.

\section{Realidade da pesquisa}

A realidade da pesquisa envolveu uma situação de formação em serviço ocorrida nos anos de 2010, 2011 e 2012. Ela foi idealizada e realizada por e para educadores de uma determinada Diretoria Regional de Ensino da Secretaria Municipal de Educação da cidade de São Paulo, no Brasil. Foi organizada por um grupo formado por representantes de unidades escolares ligados à esta diretoria, cerca de 35 profissionais, entre supervisores, diretores, coordenadores pedagógicos e professores.

0 grupo de representantes das unidades escolares reuniase periodicamente para apresentar a realidade da unidade que representava, discutir, refletir e tomar decisões em relação à proposta formativa em construção, assumindo o propósito de formação e autoformação. Esse processo culminou com três grandes encontros envolvendo cerca de 1400 educadores em cada 
um deles. Neles, foram apresentadas práticas pedagógicas bemsucedidas em forma de relatos de experiência, oficinas e pôsteres.

\section{Produção dos dados}

Uma professora de Educação Infantil e de Ensino Fundamental I da Prefeitura do Município de São Paulo, com o nome fictício de Vitória, foi a participante da pesquisa. No momento da pesquisa, ocupava o cargo de Supervisora de Ensino. Tinha 49 anos por ocasião das entrevistas, era casada, com três filhos e graduada em Pedagogia em instituição privada.

Foram realizadas duas entrevistas com a professora participante. Ela fez parte do grupo de educadores que idealizou e organizou o processo formativo em questão, sendo escolhida, no momento, como o melhor sujeito para participar da pesquisa.

Utilizou-se também, para produção dos dados, um texto construído pelo grupo de educadores para justificar a organização e realização da proposta de formação em serviço.

\section{Procedimento de análise dos dados}

Para a análise dos dados, utilizaram-se os "núcleos de significação", tais como propostos por Aguiar e Ozella (2006, 2013). Para iniciar o processo de análise, foram realizadas várias leituras das transcrições das gravações das duas entrevistas realizadas com a professora Vitória. A partir das leituras aprofundadas, seguiu-se para a construção dos Pré-indicadores, Indicadores e Núcleos de Significação. Nos Pré-indicadores destacaram-se as falas do sujeito que expressavam melhor seu pensamento. Partiu-se da fala do sujeito para realizar a análise por entender que a palavra com significado é a via de acesso para se compreender a subjetividade do sujeito e, no caso, os significados e sentidos acerca do processo de constituição da proposta de formação analisada.

Os Pré-Indicadores foram aglutinados em Indicadores, considerando-se suas semelhanças, complementaridades e possíveis contradições, de forma a condensar seus conteúdos. Tal movimento é essencial e deve ocorrer ao longo de todo o processo de análise, dado que a "parte" só se revela na articulação com o todo. 0 passo seguinte foi a organização dos indicadores para a 
construção dos Núcleos de Significação. Os critérios de aglutinação foram os mesmos, sendo que nesse momento a contradição surge como um critério essencial. A construção dos Núcleos de Significação é o momento em que a interpretação e a teorização são mais intensas, em que a teorização, essencial nesse processo, permite que se avance na produção do conhecimento.

Os núcleos de significação construídos na pesquisa revelaram, entre outras, uma característica importante na constituição do processo de formação estudada: a possibilidade de os professores mostrarem o trabalho que realizam na escola e que consideram bem-sucedido.

Em seguida, a partir das análises realizadas nos Núcleos de Significação, discute-se a relevância de dar visiblidade a trabalhos bem-sucedidos, realizados nas unidades escolares, no seu cotidiano, bem como a urgência de reflexão para alcançar possíveis mudanças que avancem na melhora da qualidade do ensino-aprendizagem. Tudo isso entendido como parte do processo de constituição de uma proposta específica de formação de educadores.

\section{0 cotidiano escolar na formação em serviço}

Segundo Heller $(1989,1994)$, a vida cotidiana traz em seu bojo a característica da alienação, ou seja, a cristalização das formas de pensar, sentir e agir que são afetadas e determinadas por uma totalidade social alienada. A autora divide a vida social humana em duas grandes esferas - a da vida cotidiana e a da vida não cotidiana - a segunda configura-se como a esfera da vida social, tendo sua gênese histórica na primeira, pois sua existência já caracteriza um certo estágio de desenvolvimento da sociedade.

Heller $(1989,1994)$ explica que a vida cotidiana é constituída a partir de três tipos de objetivações do gênero humano (objetivações genéricas em-si) que se constituem na base elementar de todo ser humano: a linguagem, os objetos (utensílios, instrumentos) e os usos (costumes) de uma dada sociedade. As esferas da vida não cotidiana se constituem a partir de objetivações humanas, ditas superiores, por serem mais complexas (objetivações genéricas para-si), como as ciências, a filosofia, a arte, a moral e a política.

Com base no raciocínio de Heller $(1989,1994)$, podemos dizer que o fenômeno de alienação ocorre quando o indivíduo restringe 
as atividades que compõem a estrutura da sua vida cotidiana ao modo reprodutor, ou seja, seu modo de pensar, sentir e agir tornam-se rígidos e personificam um comportamento cristalizado, resistindo às outras formas de posicionamentos frente à realidade em que vive.

Portanto, o cotidiano torna-se alienado e alienante numa sociedade em que não se oferecem as condições para o pleno desenvolvimento dos indivíduos que dela fazem parte, isto é, uma sociedade que não cria as condições para que os indivíduos possam se apropriar do conhecimento humano genérico. Nesse sentido, cabe salientar que na esfera do cotidiano alienado não prepondera o pensamento crítico-reflexivo, e sim a mesmice, a reiteração.

No entanto, não se pode esquecer que, ao mesmo tempo em que se reproduzem a alienação e a não reflexão, nesse mesmo cotidiano também se reproduzem as contradições sociais e, assim, as possibilidades da reflexão e, dessa forma, de transformação. Entende-se, como Heller, que o cotidiano é inescapável; pode-se dizer que ele é o caldo de fervura para as sadias rebeliões. Será nessa esfera, portanto, que tendências à desalienação poderão surgir.

Dentro dos pressupostos da proposta de formação em questão está a expectativa de superação, se não da alienação como processo constitutivo desta esfera, mas de estados de alienação, que prendem o educador no fazer reprodutivo, inerente à vida cotidiana e, consequentemente, ao cotidiano escolar.

Ela vem como uma tentativa de superação desse estado de alienação, do saber fazer mecânico - descolado da teoria. Seu foco crucial está em construir um caminho no qual o educador consiga, ao refletir criticamente sobre sua atividade educativa, visualizar de forma clara a não dicotomia teoria e prática. A atividade educativa é entendida aqui como função desempenhada por diferentes atores (educadores) que atuam dentro da área educacional, respeitando as respectivas especificidades de cada profissão (professor, coordenador, diretor, supervisor e demais funcionários de nível técnico/administrativo), mas que compartilham do mesmo espaço de trabalho.

A tentativa de superação da não dicotomia teoria e prática é um estágio no qual o educador poderá vivenciar a verdadeira práxis, pois: 
Pois o ativismo é a "prática" sem teoria e o verbalismo é a "teoria" sem prática. Isto é, o verbalismo é o falar por falar, o blá-blá-blá, o culto da palavra oca; e o ativismo é a ação pela ação, a prática cega, o agir sem rumo claro, a prática sem objetivo (SAVIANI, 2008, p. 128).

De acordo com Vázquez (2011, p. 30), o conceito de práxis ocupa o lugar central da filosofia não só como categoria para a interpretação do mundo, mas também para ajudar nas reflexões sobre como transformá-lo. E isso só é possível se for percorrido o caminho da práxis no sentido revolucionário, transformador. A proposta de formação de educadores analisada nesta pesquisa está justamente interessada nessa transformação de mundo, em criar condições nas quais os educadores possam avançar no entendimento da atividade que desenvolvem cotidianamente, superando a visão ingênua da realidade, presa às necessidades práticas e desarticulada da teoria. Para que isso ocorra, é preciso saltar da consciência comum à consciência filosófica da práxis, pois:

\footnotetext{
[... en enquanto a consciência comum não percorre a distância da consciência reflexiva não pode nutrir uma verdadeira práxis revolucionária. A consciência comum da práxis tem de ser abandonada e superada para que o homem possa transformar de forma criadora, isto é, revolucionariamente, a realidade (VÁSQUEZ, 2011, p. 35).
}

Mas, para isso, é fundamental entender a importância do cotidiano no qual o educador está inserido e respeitar seu pensamento, compreendendo assim suas limitações. Conforme aponta Vázquez:

Se nossa imagem do homem comum e corrente é fiel - desde que não percamos de vista que esse tipo de homem é um homem histórico e que, em consequência, sua cotidianidade é inseparável de uma estrutura social determinada que fixa os limites do cotidiano -, vemos que esse homem comum e corrente não deixa de ter uma ideia da práxis, por mais limitada ou falsa que possa ser. Há nele, certamente, uma consciência da práxis que se foi forjando de um modo espontâneo e irreflexivo, ainda que nela não faltem, como assinalamos, por ser consciência, certos elementos ideológicos ou teóricos em forma degradada, grosseira ou simplista. Ele tem consciência do caráter consciente de seus atos práticos, isto é, sabe que sua atividade prática não é puramente mecânica ou instintiva, e que exige certa intervenção de sua consciência; mas no que diz respeito ao verdadeiro conteúdo e significação de sua atividade, ou seja, no que se refere à concepção da própria práxis, ele não vai além da ideia antes exposta: práxis em um sentido utilitário, individual e autossuficiente (p. 37-38) 
Assim, entende-se a práxis constituída pela teoria e a prática, sendo que ambas, ao mesmo tempo em que mantém sua especificidade, se constituem mutuamente, não podendo ser apreendidas isoladamente. A proposta de formação aqui estudada assume como compromisso construir um caminho de superação dos atuais modelos de formação de educadores e, para isso, se apoia no entendimento de práxis como possibilidade de transformação, de ir além da sua atividade prática no dia a dia da escola.

Para Arroyo (2004), olhar previamente para a escola e seus professores é essencial para decidir sobre as possibilidades de inovação, ou seja, de recriar a ação docente a partir das indagações feitas sobre a identidade individual e coletiva dos educadores, entendendo que estas são constituídas na complexidade de fatores que envolvem o ensino e a aprendizagem. E um dos caminhos apontado pelo autor para conseguir a inovação educativa é o trabalho coletivo nas escolas; no caso, o autor destaca o trabalho comprometido com o questionamento sobre o currículo e suas implicações.

Pode-se entender, a partir de uma visão filosófica, utilizandose o pensamento da lógica dialética, que o "novo" surge constantemente na atividade educativa. Vieira Pinto (1979) aponta para o entendimento de que todo fato repetido é sempre novo, pois o real não pode ser repetido; portanto, todo fato é sempre um fato novo.

O autor, ao falar sobre a significação da lógica dialética, ou seja, do pensamento dialético, indispensável para compreensão dos acontecimentos no qual o homem é investigador e investigado, afirma que a lógica dialética é:

\footnotetext{
[...] indispensável para compreender todos os acontecimentos em que o homem é simultaneamente o investigador e um dos elementos do problema investigado. A presença do homem impõe o emprego da razão dialética porque a compreensão do fenômeno humano, em si mesmo e em sua atuação sobre a realidade, pertence de direito à dialética. Esta é a ciência do processo universal da realidade, suas leis estão presentes no íntimo dos seres e dos acontecimentos, mas somente na reflexão humana se faz consciente de si (1979, p.186).
}

Portanto, olhar e reconhecer a escola e seus professores foi o ponto de partida utilizado para a formação de educadores em estudo nesta pesquisa. E o caminho escolhido por educadores comprometidos em organizar uma proposta de formação em 
serviço com o desafio de criar possibilidades de transformação da atividade educativa foi propor um grande encontro, no qual as boas práticas educativas fossem visíveis além da sala de aula.

\section{A prática educativa como reconhecimento profissional}

0 grupo de educadores idealizadores da proposta de formação em pauta parecia acreditar que a formação engendrada na perspectiva crítico-reflexiva formaria um profissional que reconhecesse na educação seu potencial transformador. Contudo, sabe-se que esta não é uma tarefa fácil: há uma vasta literatura que discute os desafios de formar um profissional crítico-reflexivo (ALARCÃO, 2001; CONTRERAS, 2002; PÉREZ-GOMEZ, 1995; PIMENTA \& GHEDIN, 2012; ZEICHNER, 1993).

0 conceito de professor crítico-reflexivo está direcionado para promover a valorização do profissional da educação ao reconhecêlo como intelectual capaz de produzir conhecimentos, bem como participar ativamente das decisões ocorridas no âmbito da gestão escolar e do sistema educativo.

A característica identificada no processo de constituição da proposta de formação de educadores e explorada neste artigo foi a problematização das diversas situações do cotidiano escolar que foram trazidas à discussão coletiva. Para isso, o caminho escolhido pelo grupo de formadores foi, primeiramente, ouvir esses profissionais, percebendo o que sentem, o que pensam e como agem no cotidiano escolar.

\footnotetext{
[...] toda escola tem alguém que está trabalhando em prol desse encontro, mediando as discussões. Leva pra escola as discussões, traz o que a escola está pensando sobre isso, para que o encontro possa acontecer. A ideia é essa, para que haja esse movimento. Pra que ele possa ter frutos mesmo e que haja a participação dos professores (Entrevista com a professora Vitória).
}

A ideia dos formadores era agir a partir do cotidiano escolar, da experiência de cada professor, valorizando-o em primeiro lugar, e buscando trazer à tona problemas que impedem mudanças importantes no âmbito educacional. Segundo Heller (2008, p. 34), "a vida cotidiana não está 'fora' da história, mas no 'centro' do acontecer histórico". E completa "A vida cotidiana é a vida do indivíduo. 0 indivíduo é sempre, simultaneamente, ser particular e ser genérico". A autora também ressalta que todos os indivíduos nascem imersos na cotidianidade e que esta os absorve. 
No entanto, há momentos nas ações da cotidianidade nos quais pode haver uma suspensão do pensamento habitual. Isso ocorre, segundo a autora, em determinadas situações quando a pessoa reflete acerca de algo que acreditava, como uma superstição ou tese, e passa a não aceitá-la ao confrontá-la com a experiência e compará-la à realidade. Por fim, existe a recusa, e é nesse momento que "o referido indivíduo elevou-se acima do decurso habitual do pensamento cotidiano, ainda que apenas em tal momento" (2008, p. 52).

No processo de formação, o educador, ao trazer para o centro das discussões o cotidiano escolar e, com isso, os problemas e as decisões tomadas no seu trabalho, pode experimentar um momento de elevação do pensar habitual e, assim, ter condição para refletir sobre os problemas que enfrenta e as posições que assume na tentativa de resolvê-los no dia a dia da escola.

Saviani (2000) aponta a necessidade de refletir o que é "[...] o ato de retomar, reconsiderar os dados disponíveis, revisar, vasculhar numa busca constante de significado" (p. 16). 0 movimento de assumir a atitude de refletir sobre os problemas corriqueiros que constantemente nos pedem um posicionamento, uma tomada de decisão, para Saviani, nos aproxima dos filósofos, pois é o desafio de pensar sobre os problemas da realidade em que se vive, compreendendo problema como o de buscar respostas, que faz o homem utilizar-se da reflexão como seu melhor recurso para estruturar um posicionamento e enfrentamento da realidade.

Todavia, compreender a realidade humana é algo extremamente difícil. Implicam-se nesse processo de compreensão, especificamente da realidade da escola, marcada radicalmente pelas ideologias dominantes, inúmeros fatores que dificultam a visão do educador, pois este está inserido nessa realidade e, portanto, marcado ideologicamente por ela.

Freire (2001, p. 106) ressalta que deve haver "o esforço crítico, através do qual homens e mulheres se vão assumindo como sujeitos curiosos, indagadores, como sujeitos em processo permanente de busca, de desvelamento da razão de ser das coisas e dos fatos". E foi perseguindo esse esforço crítico, ao qual Paulo Freire se refere, que Vitória percebeu que era necessário "aprender como é chegar junto dos professores [...] conversar com os meus professores, eu preciso ouvir os meus professores pra saber o que eles querem". E assim identificou que: 


\begin{abstract}
[...] tem muita gente que parecia... meio que encapsulada. Assim, tímida, que não, não mostrava o seu potencial... E de repente você percebe 0 potencial dessa pessoa e o quanto ela tem pra colocar pra fora e o quanto ela tem colaborado. Têm aparecido, assim, pérolas e mais pérolas. Tem muita gente que fica escondida e que você percebe o quanto de potencial tem. Tem muita gente boa... Não só do grupo de organização, mas o próprio corpo docente da rede como um todo, a gente tem observado quanto trabalho bom tem e que não é dada a visibilidade que deveria se dar. E que a gente não sabe o quanto que se tem de bons trabalhos que ficam escondidos mesmo. A gente tem visto muitas pessoas com mestrado, doutorado. Mas a gente tem visto muita gente que mesmo não tendo mestrado ou doutorado é estudioso naquilo que faz. (Entrevista com Vitória)
\end{abstract}

A fala de Vitória revela quão relevante foi a oportunidade criada para o professor compartilhar sua história, apresentar o trabalho que desenvolve na escola, no seu dia a dia, e, ainda, mostrar o que realiza fora dela. Ela enfatiza: "a cada ano, a participação das escolas vem melhorando, na qualidade dos trabalhos apresentados pelos professores e também na diversidade dos trabalhos que estão sendo apresentados".

A valorização do professor, considerando-se os aspectos cognitivos e afetivos, permeou todo o processo dessa formação e colaborou significativamente para a realização e a manutenção de grandes encontros formativos ocorridos em três anos consecutivos (2010, 2011 e 2012). Os professores, ao apresentarem seus trabalhos nos encontros, pareciam sentir-se pessoal e profissionalmente valorizados, pois os encontros de formação se constituíram em espaços, segundo Vitória, que deram "visibilidade, não é projeção, no sentido midiático, mas é aquela valorização do trabalho que está sendo feito, sendo reconhecido". E ainda ressalta que a formação foi feita por e "com professores que moram na periferia de São Paulo", e que muitos deles tiveram uma formação inicial frágil, mas "estão fazendo a diferença na periferia de São Paulo".

0 propósito dessa formação carregou em si a esperança de suscitar no profissional docente o reconhecimento da sua potencialidade ao apostar numa formação que investiu na interação entre os profissionais da educação. Para Vigotski (1998), as interações, sempre sociais e historicamente constituídas, movimentam a aprendizagem e, portanto, o desenvolvimento.

Constatou-se que a proposta de formação de educadores buscou, em seu primeiro momento, partir do conhecimento prático do professor, daquilo que ele realiza com certa segurança, ou seja, 
o trabalho que realiza na escola, a prática pedagógica. Em seguida, o professor socializou esse trabalho ao apresentá-lo a seus pares. Tudo isso, segundo Vitória, proporcionou aos professores uma sensação de satisfação, uma vez que "se sentiram prestigiados, podendo mostrar o trabalho que estão fazendo e isso ajuda a eles pensarem sobre o que eles estão fazendo". Esse processo de organização aproxima-se do pensamento vigotskiano sobre a ZDI (Zona de Desenvolvimento Iminente) ${ }^{1}$ - por considerar o nível de desenvolvimento real (NDR) dos professores, ou melhor, aquilo que eles são capazes de realizar de forma autônoma.

0 próximo passo desse processo de formação, que não foi plenamente realizado, seria a discussão mais aprofundada dos trabalhos apresentados para estabelecer um diálogo com as práticas pedagógicas e realizar possíveis intervenções. Isso seria feito entre os pares e outros profissionais mais capacitados para confrontar a prática dos professores com as teorias educacionais que aparentemente lhes dão suporte. Sobre essa última etapa, Vitória explica:

\begin{abstract}
seria dialogar sobre essas práticas, fazer intervenções em cima das práticas apresentadas, ter um momento de discussão, de análise das práticas diante dessas teorias que eles dizem estar utilizando para elaboração delas, e isso a gente não conseguiu ainda, porque isso demanda também termos um grupo, principalmente da comissão, altamente competente para fazer essa mediação. (Entrevista com Vitoria)
\end{abstract}

0 trecho acima vem ao encontro do pensamento vygotskiano ao considerar o trabalho do professor, aquilo que ele já realiza de forma autônoma. Nessa linha de pensamento, acredita-se que é aberto um campo, uma zona possibilitadora de novas aprendizagens. E é nesse momento que se pode intervir de forma mais significativa e provocar um movimento mais acentuado para haver transformação da prática pedagógica e, consequentemente, do processo de ensino-aprendizagem.

Vitória acredita que o movimento necessário para transformar a realidade é primeiramente individual, porque incorre na mudança de vida da pessoa em particular para, só depois desse processo, se estender ao coletivo. Sobre isso, Vitória argumenta que:

\footnotetext{
se não mudar a concepção, se a pessoa, se a gente não conseguir, minimamente, tocar na concepção que se tem, não haverá mudança nenhuma. Então, a formação precisa tocar nesse sentido, na concepção de Homem, de vida, de vida! Enquanto você não conseguir sensibilizar pra isso, não muda. (Entrevista com Vitória)
}

1. Termo cunhado por Prestes (2010). A autora defende que a versão mais próxima do termo zona blijaichego razvitia, utilizado por Vigotski e tradicionalmente traduzido por "zona de desenvolvimento proximal", é "zona de desenvolvimento iminente", evidenciando o seu atributo fundamental: a possibilidade de desenvolvimento. 
A transformação sobre a qual Vitória se refere consiste em um movimento de superação. A superação na lógica dialética, base do pensamento deste estudo, que acontece quando o sujeito se depara com as condições reais, reconhecendo que elas são determinadas historicamente.

A partir do reconhecimento como sujeito determinado pelas condições objetivas e subjetivas impostas pela sociedade, 0 professor é provocado a refletir e encontrar novos caminhos, novos possíveis do real (CLOT, 2007) para transformação da prática docente. A transformação que a proposta de formação de educadores em questão parece perseguir, compartilhada por este estudo, é a de que a prática do professor torne-se práxis.

A práxis, de acordo com Vázquez (2011), exerce a função não apenas de interpretar o mundo, mas também de refletir em como transformá-lo, assumindo posturas revolucionárias e transformadoras. Para que isso possa ocorrer de forma efetiva, conforme mostra o processo de formação analisado, são necessárias condições adequadas a uma reflexão crítica da prática do professor.

\section{Considerações finais}

Nas análises realizadas foi constatado que a iniciativa de propiciar momentos de suspensão do cotidiano, com espaço adequado, constituído coletivamente para o profissional docente parar, olhar e pensar sobre sua prática, parece algo que necessita ser considerado nos processos formativos de professores.

Criar momentos e espaços específicos para pensar o cotidiano no qual os educadores estão absorvidos é fundamental para que possam questionar a realidade que compartilham e criar condições para transformá-la. Pimenta (2012) sinaliza como possibilidade de superação da prática e alcance da práxis a construção de um processo de conhecimento a partir da análise crítica da própria prática, com base nas teorias educacionais. Dessa maneira, o professor, a partir dos conhecimentos práticos exercidos na profissão e provocados pelas teorias, poderá ressignificar sua prática.

No processo da formação estudado, evidenciou-se também que a ideia de discutir o cotidiano escolar e socializar os trabalhos realizados pelos docentes nas unidades escolares não garante que o professor vá olhar para sua prática, refletir e transformá-la 
dentro dos pressupostos teóricos da proposta de formação da qual participa.

Para que isso ocorra, é necessário, como apontou Vitória, que haja um grupo de formadores capacitados para realizar intervenções diretamente na prática docente. 0 processo de olhar para a prática é bem complexo, não se esgota apenas na reflexão sobre as possibilidades de se fazer melhor - "consertar" o que está "errado" ou, ainda, fazer "o de costume" parecer diferente. É preciso ir além, intervir na realidade na qual o professor está submerso. Acredita-se que só assim serão criadas condições para possíveis transformações.

Com base nas análises, conclui-se que a formação de professores não é algo que deva ocorrer de forma isolada e exterior à escola. Muito pelo contrário, ela deve ser gerada na instituição educativa, constituída pelo grupo de educadores. A questão é saber como formar um coletivo transformador dentro de escolas que estão imersas em suas culturas, muitas vezes distantes e resistentes a qualquer mudança; com professores mergulhados em práticas cristalizadas e imobilizados por inúmeras questões pessoais e profissionais - que se fazem presentes no cotidiano e na prática como impeditivos de transformação.

Por fim, devemos destacar ainda que os aspectos identificados e teorizados neste estudo poderão ser estendidos para compreensão de outras propostas de formações implementadas nas diferentes redes de ensino, bem como contribuir nos estudos realizados sobre formação de professores. No entanto, permanecem alguns questionamentos que merecem ser investigados com maior profundidade, como, por exemplo, as implicações que essa proposta de formação de educadores trouxe à prática dos professores que dela participaram. Que diferença fez essa formação na vida desses profissionais? Como esses profissionais avaliaram a formação em sua vida profissional? Ter participado da formação contribuiu para repensar a prática do professor? Será que ocorreu, efetivamente, alguma transformação na prática docente?

Os questionamentos levantados apontam para a necessidade de dar continuidade e aprofundamento nos estudos sobre as propostas atuais de formação de professores. Ao apresentar uma estutura de formação diferenciada, o estudo, longe de oferecer um modelo, coloca em debate o papel do professor no processo formativo. 


\section{REFERÊNCIAS}

AGUIAR, W. M. J.; OZELLA, S. Núcleos de significação como instrumento para a apreensão da constituição dos sentidos. Psicol. cienc. prof. [online]. 2006, v.26, n.2, pp. 222-245. ISSN 1414-9893

Apreensão dos sentidos: aprimorando a proposta dos núcleos de significação. Revista Brasileira de Estudos Pedagógicos. Brasília, v. 94, n. 236, p. 299-322, jan./abr. 2013.

ALARCÃO, Isabel (org.). Escola reflexiva e nova racionalidade. Porto Alegre: Artmed, 2001.

ARROYO, Miguel G. Imagens quebradas - trajetórias e tempos de alunos e mestres. 4. ed. Petrópolis: Vozes, 2004.

BOCK, A. M. B: Aventuras do Barão de Münchhausen na psicologia. Ed. Cortez: São Paulo, 1999.

CONTRERAS, J. A autonomia de professores. Tradução Sandra Trabucco Valenzuela. São Paulo: Cortez, 2002.

CLOT, Y. A função psicológica do trabalho. Tradução: Adail Sobral. 2. ed. Petrópolis, RJ: Vozes, 2007.

FREIRE, P. Política e educação: ensaios. 5. ed. São Paulo: Cortez, 2001.

HELLER, A. Cotidiano e história. Rio de Janeiro: Paz \& Terra, 1989. Cotidiano e história. Rio de Janeiro: Paz \& Terra, 2008 Sociologia de la vida cotidiana. 4. ed. Barcelona: Península, 1994.

NÓVOA, A. Relação escola-sociedade: novas respostas para um velho problema. In: SERBINO, R. V. et al. (Orgs). Formação de professores. São Paulo: UNESP, 1998, p.19-40.

PÉREZ GÓMEZ, A. O pensamento prático do professor: a formação do professor como profissional reflexivo. In: NóvoA, Antonio (org.). Os professores e sua formação. Lisboa: Publicações Dom Quixote, 1995, p.93-114. 
PIMENTA, S.G.; GHEDIN, E. (Orgs.) Professor reflexivo no Brasil: gênese e crítica de um conceito. São Paulo: Cortez, 2012.

SAVIANI, D. Educação: do senso comum à consciência filosófica. Campinas: Autores Associados, 2000, 13ª Edição. História das idéias pedagógicas no Brasil. 2.ed. Campinas: Autores Associados, 2008.

SEVERINO, A. J. Educação, sujeito e história. São Paulo: Olho d'Água, 2002.

SZYMANSKI, H. (Org). A entrevista na pesquisa em educação: a prática reflexiva. 4. ed. Brasília: Liber Livro Editora, 2011.

VÁZQUEZ, A. S. Filosofia da Práxis. 2. ed. Buenos Aires: Consejo Latinoamericano de Ciencias Sociales. Clacso: São Paulo: Expressão Popular, Brasil, 2011.

VIGOTSKI, L.S. A formação social da mente: o desenvolvimento dos processos psicológicos superiores. 7. ed., São Paulo: Martins Fontes, 2007.

VIEIRA PINTO, A. A necessidade da compreensão filosófica da pesquisa científica. Ciência e Existência: problemas filosóficos da pesquisa científica, v. 2, 1979.

ZEICHNER, K. M. A formação reflexiva de professores: ideias e prática. Lisboa: Educa, 1993.

Recebido em: 23/07/2014

Revisto em: 18/09/2014

Aprovado em: 23/09/2014 